\title{
FRAGILITY OF FLOATING DOCKS FOR SMALL CRAFT MARINAS
}

\author{
Adam Keen ${ }^{1}$, Patrick Lynett ${ }^{2}$, Martin Eskijian ${ }^{1}$ and Aykut Ayça ${ }^{1}$
}

\begin{abstract}
As a result of damage from the 2010 Chile and 2011 Japanese teletsunamis, the tsunami risk to the small craft marinas in California has become an important concern. This paper outlines an assessment tool which can be used to assess the tsunami hazard to small craft harbors. The methodology is based on the demand and capacity of a floating dock system. Results are provided as fragility curves and give a quantitative assessment of survivability. This tool is not exact and is provided only to give an indication as to survivability and/or failure of a floating dock system of vessels and floating components/piles, subject to tsunami events. The purpose is to quickly evaluate whether or not a floating dock is likely to survive or be destroyed by a tsunami having the input properties.
\end{abstract}

Keywords: small-craft harbor risks; tsunami damage; stochastic modeling

\section{INDRODUCTION}

Tsunamis pose a significant risk to infrastructure located along the coast of California. While, the frequency of significant tsunami events is small compared with other natural hazards, the impact of tsunami events (especially to small craft harbors) is high. It is this interplay between frequency and impact which drives the tsunami risk. Because of the damage resulting from the 2010 Chile and 2011 Japanese teletsunamis, the tsunami risk to the small craft marinas in California has become an important concern. Damage estimates from the two events been estimated to be up to \$150 million. The State of California seeks to mitigate subsequent damage from the next major tsunami that might strike the Pacific Coast.

This paper will outline an assessment tool which can be used to assess the tsunami hazard to small craft harbors. The methodology is based on the demand and also the structural capacity of the floating dock system, composed of floating docks/fingers and moored vessels. Because of the uncertainties in the current direction, the exact current speed, and the remaining capacities of the floating structure, a Monte Carlo approach has been employed. The equations used to determine the forces on the vessels and floating structure are taken from conventional sources, and the system of vessels, floating components and piles are all included in the assessment. The condition of the floating dock structure is included, and a demand/capacity ratio is used as an index of failure. Results are provided as fragility curves and give a quantitative assessment of survivability.

\section{STATSICTICAL METHODOLOGY}

The Monte Carlo methodology is a probabilistic computational tool where the governing equations of motion and/or structural behavior might be well known, but the independent variables of the input (demand) as well as the resisting structural components (capacity) may not be completely known. The Monte Carlo approach uses a distribution of each variable, usually with a rectangular, triangular or Gaussian shaped relationship of the variable, and then uses that random variable within the described parameters, to generate a single computation. The process then repeats hundreds or thousands of times. And for this initial effort, a rectangular distribution of each variable is used (e.g. equal probability of any value within the range). The results of the individual simulations are then used to construct a fragility curve of probability of failure. In this case the structural demand/capacity ratio is used as one index and the other one is a measure of failure/survival based on gross behavior. A fragility curve is estimated for pile guides which are most likely to fail during a tsunami.

\section{Data Requirements}

Depending on the certainty of the parameter, inputs to the Monte Carlo model can be defined as either deterministic or probabilistic. Deterministic quantities are those quantities which are known or are not expected to vary within a scenario. With regard to the floating docks these include: finger length, finger width, number of slips and number of piles. Effectively, this implies that the analysis is being performed as a damage assessment on the harbor as it exists presently; potential future change to the harbor layout might also be included in a probabilistic manner but will be addressed in future work. For this analysis within California, these quantities were estimated from historical high-resolution orthoimagery data available from the United States Geological Survey (USGS).

In contrast to deterministic inputs, probabilistic inputs are those quantities which might not be exactly known but can be defined by a probability density function. These quantities would include:

\footnotetext{
${ }^{1}$ Sonny Astani Department of Civil and Environmental Engineering, University of Southern California, $3620 \mathrm{~S}$.

Vermont Avenue, Los Angeles, CA 90089, USA

${ }^{2}$ California State Lands Commission, 200 Oceangate, Suite 900, Long Beach, CA 90802, USA
} 
current speed, current direction, water depth, sea water density, vessel length, vessel beam, vessel draft. Each input variable was randomized assuming a rectangular probability density function (e.g. equal probability of any value within range) bounded by defined minima and maxima. Current speed and current direction were estimated from a high-resolution numerical model (to be discussed in more detail in later sections). Model results were finely sampled using the parameter surface to define the approximate minimum and maximum within the confines of each slip.

\section{Demand to Capacity Equations for Pile Guides}

The governing equations for the transverse and longitudinal forces on vessels were used to calculate the "demand" from the tsunami current (U.S. Army Corps of Engineers, Naval Facilities Engineering Command, and Air Force Civil Engineer Support Agency 2005) assuming that a floating dock acts similarly to a vessel. The equations to determine the current forces on the vessels are summarized in this section. The approach is intended to be first order such that differential loads are not treated in this phase of the analysis.

For the transverse current forces on a vessel (U.S. Army Corps of Engineers, Naval Facilities Engineering Command, and Air Force Civil Engineer Support Agency 2005):

$$
F_{y c}=\frac{1}{2} \rho_{w} V_{c}^{2} L_{w l} T C_{y c} \sin \theta
$$

where: $\rho_{w}=$ water density; $V_{c}=$ current velocity; $L_{w l}=$ length of the vessel at the waterline; $T=$ vessel draft; $C_{y c}=$ transverse drag coefficient; and $\theta=$ angle of velocity relative to the vessel longitudinal axis.

The transverse drag coefficient was estimated from (U.S. Army Corps of Engineers, Naval Facilities Engineering Command, and Air Force Civil Engineer Support Agency 2005):

$$
C_{y c}=C_{0}+\left(C_{1}-C_{0}\right)\left(\frac{T}{d}\right)^{2}
$$

where: $C_{0}=$ deepwater current drag coefficient for $T / d \approx 0 ; C_{1}=$ shallow water drag coefficient $(=$ 3.2); and $d=$ water depth. The deepwater drag coefficient can be estimated from:

$$
C_{0}=0.22 \sqrt{\chi}
$$

With $\chi$ defined as:

$$
\chi=\frac{L_{w l}^{2} A_{m}}{B V}
$$

where: $A_{m}=$ immersed cross-sectional area of the vessel at midsection; $B=$ maximum vessel beam at the waterline; and $V=$ submerged volume of vessel.

Similarly, for the longitudinal current forces on the vessel, not considering propeller loads which could be highly variable (U.S. Army Corps of Engineers, Naval Facilities Engineering Command, and Air Force Civil Engineer Support Agency 2005):

$$
F_{x C}=F_{x \text { FORM }}+F_{x \text { FRICTION }}
$$

And:

$$
F_{x F O R M}=\frac{1}{2} \rho_{w} V_{c}^{2} B T C_{x c b} \cos \theta
$$

where: $C_{x c b}=$ longitudinal current form drag coefficient $(=0.1)$. And,

$$
F_{x \text { FICTION }}=\frac{1}{2} \rho_{w} V_{c}^{2} B S C_{x c a} \cos \theta
$$

where: $S=$ wetted surface area; $C_{x c a}=$ longitudinal current skin friction coefficient. Here, the wetted surface area is estimated by: 


$$
S=1.7 T L_{w l}^{2}+\left(\frac{D}{T \gamma_{w}}\right)
$$

where: $\gamma_{w}=$ weight density of water. And the longitudinal current skin friction is a function of Reynold's number defined as:

$$
C_{x c a}=\frac{0.075}{\left(\log _{10} R_{N}-2\right)^{2}}
$$

where: $R_{N}=$ Reynolds number. For vessels, the Reynolds number is defined as:

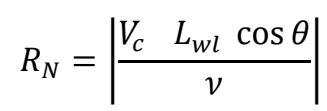

where: $v=$ kinematic viscosity of water.

Floating docks and fingers resist the tsunami “demand” via the pile guide. For this analysis, forces on the pile guides are determined based upon the demand equation. The demand is then averaged based upon the number of pile guides to determine the load per pile guide. Multiple pile guides within a dock system resist horizontal loads while allowing the dock to adjust to a rising and falling tide. For the pile guide capacity, a typical pile collar within California consists of between 4 and 8 bolts which connect to the dock via a timber connection. By knowing the size and number of bolts, capacities for each pile guide can be directly estimated. However, even if the exact configuration of pile guides by dock is known, it is nearly impossible to accurately quantify the in-situ pile guide "capacities". Therefore, the results are presented with respect to the "required capacity" which can be interpreted as the capacity needed to resist the tsunami demand.

\section{NUMERICAL MODELING OF TSUNAMI EVENTS}

Santa Cruz Harbor is a small municipal harbor located along the Central California coast. The harbor consists of two long and narrow basins that extend inland from the shoreline. The north and south basins were built nearly a decade apart which resulted in differences in material construction between the two basins. The south basin was completed in 1963, was originally built using timber deck materials and piles typical of the period. By the time the north basin was completed in 1972 floating dock construction had changed favoring a more robust composite type construction (Mesiti-Miller Engineering Inc. 2011).

Since the harbor's completion, very few of the docks had been replaced leaving the harbor vulnerable to tsunami events. During the 2011 Tohoku tsunami, a series of waves caused significant damage to Santa Cruz Harbor. Numerical models of tsunami events were analyzed for Santa Cruz Harbor to assess the harbor's vulnerability using the Monte Carlo methodology. One scenario was the 2011 Tōhoku tsunami that damaged almost all docks within Santa Cruz Harbor.

Hydrodynamic modeling for this study was conducted using the numerical model "Method of Splitting Tsunamis” (MOST) (Titov and Gonzalez 1997; Titov and Synolakis 1998). The model can simulate the full development of the tsunami from wave generation to wave run-up. Tsunami propagation is modeled based upon the elastic deformation theory (Okada, 1985) while inundation is modeled based upon a derivation of the VTCS model (Titov and Synolakis, 1998). The model has been extensively validated for several global scenarios. Variants of the MOST model have been in constant use for tsunami hazard assessments in California since the mid-1990s (Lynett et al. 2014). The reader is reader is referred to Titov and Gonzalez (1997) for further information on the model as well as general validation.

In this study, MOST is used to propagate tsunami waves from source to the nearshore region, using a system of nested grids. The outermost grid at 4 arc min resolution covers the entire Pacific basin. Three additional grids of increasingly finer resolution were derived from data provided by National Oceanic and Atmospheric Administration's (NOAA) National Geophysical Data Center specifically for tsunami forecasting and modeling efforts (Grothe et al. 2012). The innermost nearshore grid has a $10 \mathrm{~m}$ resolution and takes boundary input from the previous MOST nested layer.

While model predictions of surface elevation are commonly compared with tide gauge data, comparisons with current speed are less common, principally due to the lack of data. Therefore, the MOST modeling work for Santa Cruz Harbor was validated against the high-order Boussinesq-type model Cornell University Long and Intermediate Wave Modeling Package (COULWAVE) (Lynett et al. 2014). Model results suggest that while not as accurate as the higher-order COULWAVE model, the 
MOST tsunami model satisfactorily reproduces measured tsunami-induced current speeds (Lynett et al. 2014).

The 2011 magnitude 9.0 Japan event was selected as the primary event because of amount of damage caused by that event and documentation available to validate the methodologies. The 2011 Tōhoku earthquake was a magnitude 9.0 which occurred on March 11, 2011. The epicenter of the earthquake was approximately $70 \mathrm{~km}$ east of the Oshika Peninsula of Tohoku. The nature of the seismic event generated a powerful tsunami the impacts of which were felt throughout the Pacific Basin. In the far field, many ports, harbors, and maritime facilities along the U.S. West Coast was adversely affected by surges and currents induced by the 2011 Tōhoku tsunami (Wilson et al., 2012; Wilson et al. 2013).

The tsunami reached Santa Cruz approximately ten hours after the seismic event, creating strong currents within the harbor. Santa Cruz Harbor experienced strong currents starting the morning of March 11, 2011 and continuing through to the afternoon of March 12, 2011. There were no measured currents available within the harbor, however, eyewitness reports and post-event video analysis indicated current speeds of up to $4 \mathrm{~m} / \mathrm{s}$ as the tsunami entered the harbor (Ewing, 2011), and maximum current speeds within the harbor of $5-7 \mathrm{~m} / \mathrm{s}$ just north of the two central bridges which separate the north and south harbor (Wilson et al. 2012).

Source terms for the 2011 Tōhoku tsunami were taken from Shoa et al. (2011). Modeled maximum currents speeds for Santa Cruz North Harbor and South Harbor are shown in Figure 1. The model results show significant heterogeneity in the current field with the strongest currents occurring at the harbor entrance and in the channel transition from the south to north harbor. The model results also agree reasonably well with maximum observed current speed being on the order of $3.5 \mathrm{~m} / \mathrm{s}$.
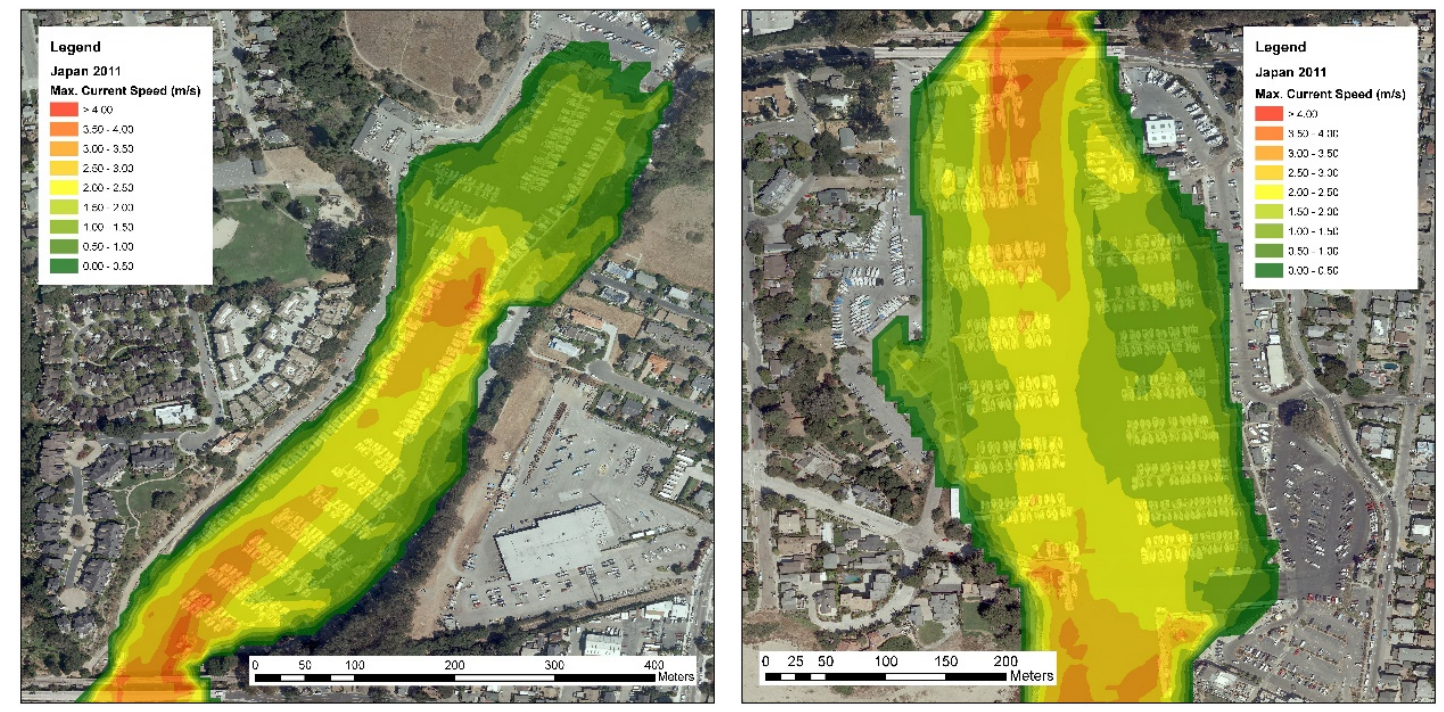

Figure 1. Maximum modeled current speed within Santa Cruz North (left) and South (right) Harbor for the 2011 Tōhoku tsunami event

\section{POST TSUNAMI DAMAGE ASSESSMENT}

After the 2011 Tōhoku tsunami event, the Santa Cruz Port District hired Mesiti-Miller Engineering Inc. to conduct a damage evaluation of all fixed and floating facilities for the small craft harbor. The assessment consisted of a visual assessment of all floating facilities supported by guide piles; fixed structures within Santa Cruz were not included. Typical damage to the dock facilities included loose/missing flotation, cleats being pulled out from the dock, cracked whalers and broken pile guides.

Mesiti-Miller Engineering Inc. gave each dock within Santa Cruz a rating from A to F with A representing little/no damage and F representing complete failure. From this assessment, Mesiti-Miller Engineers Inc. concluded that every floating dock suffered some degree of damage (Mesiti-Miller Engineering Inc. 2011). The ratings developed by Mesiti-Miller Engineering Inc. were further used to develop low, medium and high damage ratings for each dock within Santa Cruz Harbor. The low category corresponds to a rating from A-B, the medium category corresponds to rating from C-D and high category corresponds to a rating of $\mathrm{F}$. A polygon representing the boundaries of each dock was estimated from USGS aerial images then color coded with the corresponding damage level. The result is a spatial map of damage within north and south Santa Cruz Harbor (see Figure 2). 

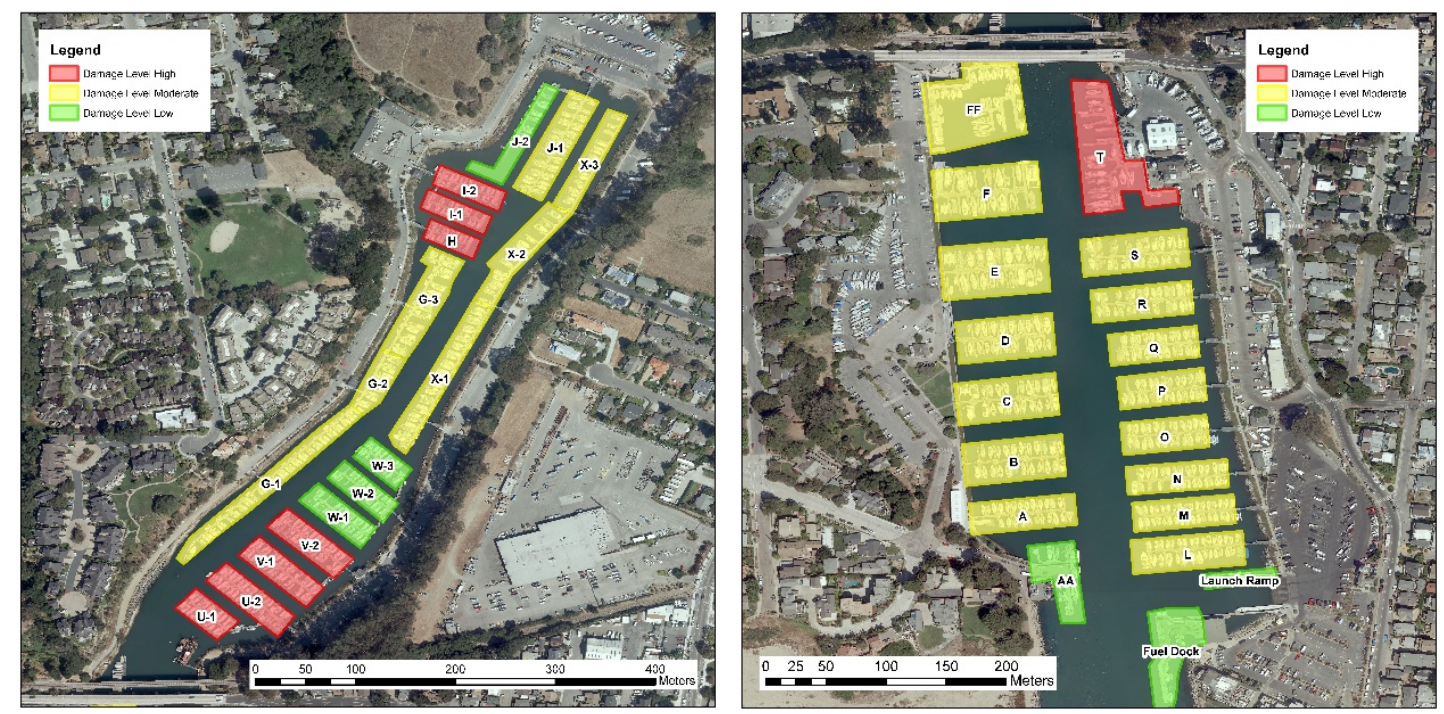

Figure 2. Damage survey of the Santa Cruz Harbor north (left) and south (right) basins showing areas of high (red), medium (yellow) and low (green) slip damage.

The north harbor sustained the most severe damage during the tsunami event. The damage within the basin however, was spatially heterogeneous with some areas experiencing little or no impacts while other docks were destroyed. Docks W-1, W-2 and W-3 sustained no damage during the tsunami event and are shown in green. Docks U-1, U-2, V-1 and V-2 sustained a high degree of damage and are shown in red. Eyewitness accounts have indicated that damage at these docks occurred early in the tsunami event. Docks H, I-1 and I-2 also sustained a high degree of damage. However, these docks were damaged by debris which had accumulated within the harbor as a result of the initial waves. This type of damage is considered beyond the scope of this study.

Most of the South Harbor sustained moderate damage during the tsunami event. The exception to this would be dock AA, the fuel dock and the launch ramp, which were not damaged during the event. This is likely because these are fixed structures, not floating docks like the rest of the harbor. MesitiMiller Engineering attributes the difference in damage between the two harbors to the differences in infrastructure ages between the north and south basin.

\section{POST-TSUNAMI HAZARD ASSESSMENT}

A hindcast assessment of the 2011 tsunami event was conducted using the methodology outlined in previous sections. Current speeds and directions from each event were taken from the model results. One key weakness of this analysis is that the capacities of each component prior to the 2011 event were not known. Therefore, each fragility curve is given in terms of the required capacity for damage to occur. The output capacities can be correlated with the event damage from the previous section. The curves can be used to infer component capacities, and then be used by engineers to assess under what scenarios damage to a harbor could occur. Only a limited number of docks were analyzed to validate the methodology with docks selected based upon the characteristics of the flow field, dock location within the harbor and layout.

Fragility curves for pile guides from the Monte Carlo analysis are presented in Figure 3. The results are presented with respect to the required capacity which can be interpreted as the capacity needed to resist the tsunami demand. The scatter plot in the bottom panel corresponds to the $95 \%$ confidence level of each fragility curve by dock, or the capacity that we can state with $95 \%$ confidence would lead to a component failure for the particular tsunami scenario. 

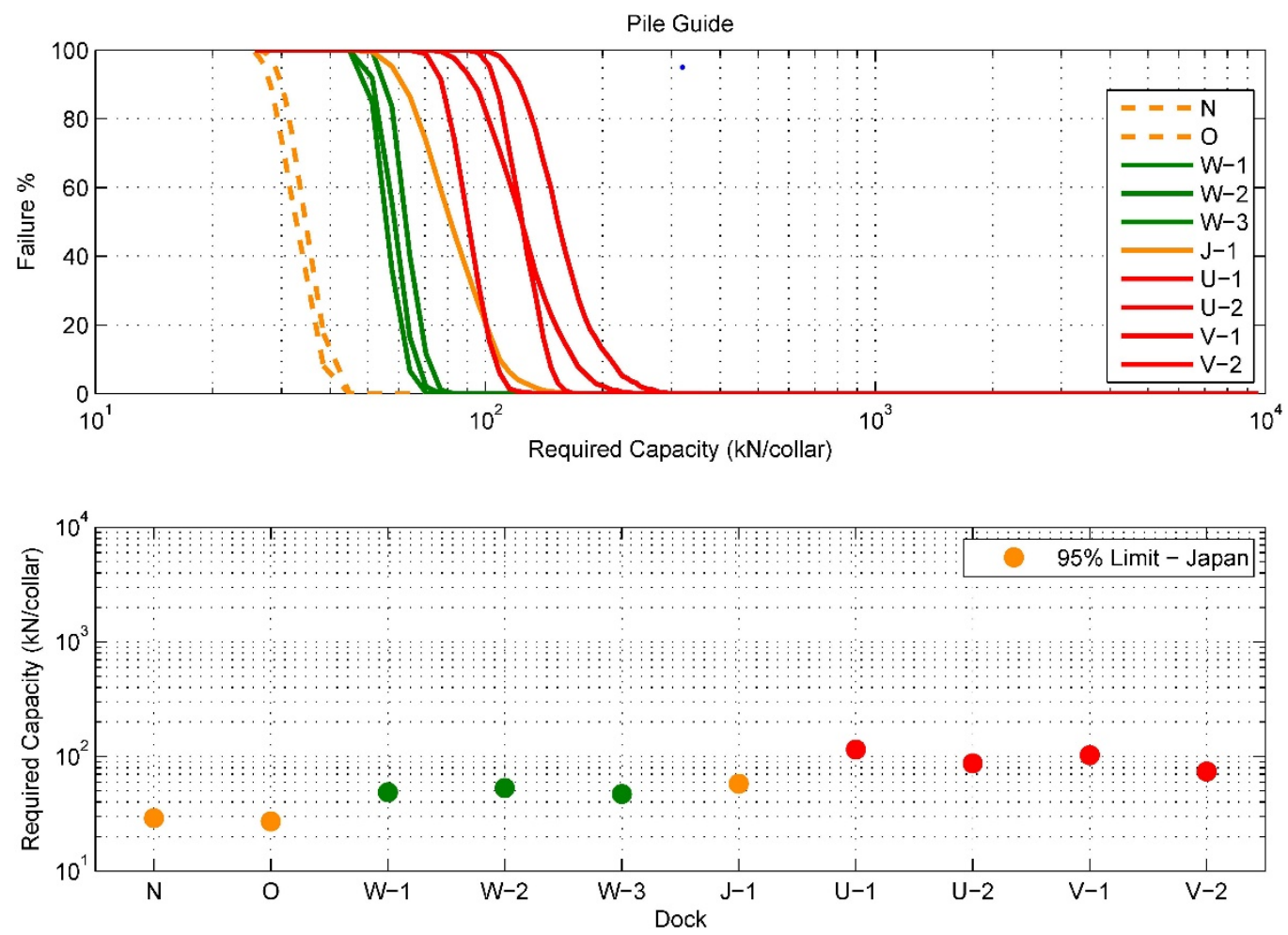

Figure 3. Fragility curves for pile guides in Santa Cruz Harbor for the 2011 Tōhoku event (top); fragility curve 95\% confidence limits for the 2011 Tōhoku (bottom). Green, yellow and red fragility curves and markers correspond to low, medium and high levels of observed damage for the 2011 Tōhoku event.

In this figure, green, yellow and red fragility curves correspond to low, medium and high levels of damage, as taken from the damage report, for the 2011 Tōhoku event. Assuming that all pile guides have the same structural capacity, the Monte Carol results should show an increasing trend for required capacity from green, to yellow to red. The reason for this expectation is that, if all components have the same structural capacity, those components that were not damaged (green curves) should have needed a relatively small required capacity to prevent failure, or equivalently experienced a relatively small demand. Conversely, those components that were damaged (red curves) should have needed a relatively large capacity, in fact a capacity beyond the structural capacity, to prevent failure. However, the results show a noticeable difference between the north (solid lines) and south (dashed lines) basins. The difference in the capacities required to resist failure of the south basin are significantly less than those of the north. This can be attributed to the difference in age of the two basins. With the south being finished in approximately 1962 and being constructed of mostly wood while the north was finished in approximately 1973 and was constructed of mostly composite, the results indicate that the capacity of the wood docks was likely less than the composite docks. This result highlights the need to understand (or at the very least have means to differentiate) the underlying structural capacity of the system independent of the system demand.

Focusing just on the north basin, these results also show three distinct regimes in line with low, medium and high levels of damage from the post tsunami survey. These can be used to see when and where the transition from no damage to damage could be. For instance, the results for dock J-1 and W-2 had nearly the same required capacity but were classified as low and moderate levels of damage. This result would, therefore, tend to suggest that the transition between low to moderate damage is somewhere between the two results. Similarly, this implies that the structural capacity of pile guides in the north basin was also likely near the Monte Carol predicted required capacity of the J-1 and W-2 docks.

\section{CONCLUSION}

This paper outlines an assessment tool that can be used to quantify the tsunami hazard to small craft harbors. The methodology is based on the demand-to-capacity ratio of a floating dock system. The results of the analysis highlight the skill of the Monte Carlo methodology to predict tsunami damage within a small craft harbor. When coupled with a damage report, the method was able to predict the grouping of areas of high, medium and low damage as well as differentiate between underlying structural capacities 
in different areas of the same harbor. Once calibrated, fragility curves for other events can be developed and used by engineers to determine the capacity required to withstand the design event. Eventually a suit of scenarios could be analyzed to determine in a probabilistic sense what the required dock capacities should be in order to withstand extreme events.

\section{ACKNOWLEDGMENTS}

Primary support for this work has been provided by the Federal Emergency Management Agency under a cooperative technical partnership with the State of California.

\section{REFERENCES}

Ewing, L. (2011). "The Tohoku Tsunami of March 11, 2011: A Preliminary Report On Effects to the California Coast and Planning Implications.” California Coastal Commission Memo.

Grothe, P. G., Taylor, L. A., Eakins, B. W., Carignan, K. S., Friday, D. Z., and Love, M. (2012). "Digital Elevation Models of Monterey, California: Procedures, Data Sources and Analysis.” < www.ngdc.noaa.gov/dem/report/download/4470>.

Lynett, P. J., Borrero, J., Son, S., Wilson, R., and Miller, K. (2014). "Assessment of the tsunami-induced current hazard.” Geophysical Research Letters, 41(6), 2048-2055.

Mesiti-Miller Engineering Inc. (2011). “Tsunami Damage Evaluation of All Fixed and Floating Facilities at the Santa Cruz Small Craft Harbor.” Consulting report for the Santa Cruz Port District. MME 11118. (Mar. 21, 2016).

Okada, Y. (1985). "Surface deformation due to shear and tensile faults in a half-space.” Bulletin of the Seismological Society of America, 75(4), 1135-1154.

Santa Cruz Port District. (2016). "Harbor user groups." History of the Harbor. $<$ http://www.santacruzharbor.org/historyoftheharbor.html>. (Sep. 19, 2016).

Titov, V. and Synolakis, C. (1998). "Numerical modeling of tidal wave runup." Journal of Waterway, Port, Coastal, and Ocean Engineering, 10.1061/(ASCE)0733-950X(1998)124:4(157), 157-171.

Titov, V. V., and González, F. I. (1997). "Implementation and testing of the Method of Splitting Tsunami (MOST) model.” NOAA Tech. Memo. ERL PMEL-112.

U.S. Army Corps of Engineers, Naval Facilities Engineering Command, and Air Force Civil Engineer Support Agency. (2005). “Design: Moorings.” Unified Facilities Criteria. UFC 4-159-03.

Wilson, R., Davenport, C., and Jaffe, B. (2012). "Sediment scour and deposition within harbors in California (USA), caused by the March 11, 2011 Tohoku-oki tsunami.” Sedimentary Geology, 282, 228-240.

Wilson, R. I., Admire, A. R., Borrero, J. C., Dengler, L. A., Legg, M. R., Lynett, P., and Whitmore, P. M. (2013). "Observations and impacts from the 2010 Chilean and 2011 Japanese tsunamis in California (USA).” Pure and Applied Geophysics, 170(6-8), 1127-1147. 